\title{
Glokom Hastalığının Evrişimli Sinir Ağı Mimarileri ile Tespiti
}

\section{Diagnosis of Glaucoma Disease using Convolutional Neural Network Architectures}

\section{Murat Uçar 1*i(D)}

${ }^{1}$ İskenderun Teknik Üniversitesi, İşletme ve Yönetim Bilimleri Fakültesi, Yönetim Bilişim Sistemleri Bölümü, Hatay, TÜRKIYE

Sorumlu Yazar / Corresponding Author*: murat.ucar@iste.edu.tr

\author{
Geliş Tarihi / Received: 27.06.2020 Arastırma Makalesi/Research Article \\ Kabul Tarihi / Accepted: 27.11.2020 DOI:10.21205/deufmd.2021236815 \\ Atıfșekli/How to cite: UÇAR M. (2021). Glokom Hastalığının Evrişimli Sinir Ağı Mimarileri ile Tespiti. DEÜFMD 23(68), 521-529.
}

\section{Öz}

Glokom, genellikle göz içi basıncının yükselmesi nedeniyle optik sinire zarar veren bir hastalıktır ve dünya genelinde geri döndürülemez körlüğün yaygın bir sebebidir. Ancak hastalık erken dönemde tespit edilebilirse görme kaybı önlenebilmektedir. Günümüzde glokom hastalığının tanısı, gelişmiş yapay zeka teknikleri kullanılarak bilgisayar destekli sistemler yardımıyla yapılabilmektedir. Bu çalışmada, yeni oluşturulmuş büyük ölçekli bir veri setine ait dijital fundus görüntüleri kullanılarak otomatik glokom tespiti için derin evrişimli sinir ağları yöntemi kullanılmıștır. Literatürde sınıflandırma problemlerinde en sık kullanılan mimarilerden VGG16, Inception-V3, EfficientNet, DenseNet, ResNet50 ve MobileNet mimarileri seçilmiștir. Deneysel çalışmalar sonucunda DenseNet mimarisinin \%96.19 ile en yüksek bașarı oranını elde ettiği görülmüștür. Elde edilen bulgular evrişimli sinir ağlarının normal ve glokomlu görüntüleri sınıflandırmada başarılı bir yöntem olduğunu kanıtlamıştır.

Anahtar Kelimeler: Glokom, Derin öğrenme, Evrișimli sinir ağları, Transfer öğrenimi

\section{Abstract}

Glaucoma is a disease that damages the optic nerve, often due to increased intraocular pressure, and is a common cause of irreversible blindness worldwide. However, if the disease can be detected in the early period, vision loss can be prevented. Today, the diagnosis of glaucoma disease can be made with the help of computer-aided systems using advanced artificial intelligence techniques. In this study, deep convolutional neural networks were used for automatic glaucoma detection using digital fundus images of a newly created large-scale data set. VGG16, Inception-V3, EfficientNet, DenseNet, ResNet50 and MobileNet architectures which are the most frequently used architectures in classification problems were selected. As a result of experimental studies, it was seen that the DenseNet architecture achieved the highest accuracy rate with $96.19 \%$. The findings have proven that convolutional neural networks are a successful methods on classification of normal and glaucoma images.

Keywords: Glaucoma, Deep learning, Convolutional neural networks, Transfer learning 


\section{Giriş}

Glokom, sağlıklı görebilmemiz için hayati öneme sahip olan optik sinire zarar veren bir grup göz hastalığıdır. Bu zarar genellikle gözdeki çok yüksek bir basınçtan kaynaklanmaktadır. 2020 yılında 76 milyon, 2040 yılında ise 111.8 milyon insanın glokomdan etkilenmesi beklenmektedir [1]. Maalesef hastalığın son aşamasına kadar fark edilmeden ilerleyebilen glokom, geç teșhis edildiğinde kalıcı körlüğe neden olmaktadır. Şu anda henüz bir tedavisi olmaması nedeniyle, gözde görme kaybını önlemek için glokomun erken teşhis edilmesi önemlidir.

Derin öğrenme yöntemleri son yıllarda tıbbi ve oftalmolojik görüntülerde nesne tanıma görüntü sınıflandırma ve bölütleme konularında sıklıkla kullanılmış ve çok başarılı sonuçlar elde edilmiștir. Özellikle derin evrișimli sinir ağları (ESA), retinal görüntülerden diyabetik retinopati, yaşa bağlı maküler dejenerasyon ve glokom gibi retinal hastalıkların erken teşhisi ve tanımlanması gibi görevler için kullanılmıștır $[2,3,4]$.

$\mathrm{Bu}$ çalışmada fundus görüntülerinden glokom hastalığını saptamak için evrişimli sinir ağları yöntemi kullanılmıştır. Bu bağlamda literatürde sık kullanılan ve yüksek doğruluk sonucu elde edilen Visual Geometry Group-16(VGG16), Inception-V3, EfficientNet, Densely Connected Convolutional Network(DenseNet), Residual Neural Network(ResNet50) ve MobileNet mimarileri kullanılmıștır.

$\mathrm{Bu}$ makalenin geri kalanı aşağıdaki gibi düzenlenmiștir. Bölüm 2'de ilgili çalıșmalar sunulmuștur. Bölüm 3'te, çalıșmada kullanılan veri seti ve önerilen yöntemler ayrıntılı olarak açıklanmıștır. Bölüm 4'te, çalıșmada elde edilen sonuçlar ve literatürdeki benzer çalışmalara ait bulgularla karșlaștırılması sunulmuștur. Makalenin tartıșma ve sonuç bölümü Bölüm 5'te sunulmuştur.

\section{Literatür Taraması}

Son yıllarda glokom hastalığının teşhisi için derin öğrenme tabanlı yöntemleri öneren çalışmalar yapılmaktadır ancak sınırlı sayıdadır. Glokom tanısı için derin öğrenme modellerini kullanan çalışmalar iki türe ayrılabilir.

Birinci türde yapılan çalışmalar glokom tanısını doğrudan derin öğrenme modellerini kullanarak gerçekleştirir. Chen ve arkadaşları glokom tanısı için altı katmanlı bir evrişimli sinir ağı yapısı kullanmıș ve önerdikleri modeli ORIGA ve SCES veri setleri üzerinde test etmișlerdir [4]. Raghavendra ve arkadaşları glokomun tanısı için derin öğrenme temelli yeni bir model geliştirmiştir. Geliştirilen model dijital fundus görüntülerinden özellik çıkarımı için on sekiz katmanlı bir evrișimli sinir ağı kullanmıștır. Daha sonra elde ettikleri bu özellikleri test aşamasında normal ve glokom olarak sınıflandırmışlardır. Geliştirilen bu model \%98.13 'lük bir doğruluk oranı elde etmiştir [5]. Bir bașka çalıșmada Chai ve arkadașları glokom tanısı için çok branşlı bir sinir ağı modeli önermișlerdir. Önerilen modelin aynı anda hem görüntülerin çok fazla bilgi içeren önemli alanlarını otomatik olarak ayırt edebildiğini hem de görüntüden gizli özellikleri çıkarabildiğini bildirmişlerdir. Önerilen modeli gerçek veri setleri üzerinde test ettiklerinde 0,9151'lik bir başarı elde etmişlerdir [6]. Fu ve arkadașları otomatik glokom tanısı için farklı ESA'ları birleștiren yeni bir topluluk ağı önermiștir. Önerdikleri modeli ORIGA veri setinde bulunan görüntülerle eğitmiș SCES ve SINDI veri setleri üzerinde test etmişlerdir. Önerilen modelin diğer algoritmalardan daha iyi bir performans gösterdiğini bildirmişlerdir [7]. Li ve arkadaşları glokom tespiti için öncelikle büyük ölçekli bir veri seti olușturmuș daha sonra dikkat temelli bir model geliştirerek evrişimli sinir ağlarıyla birleștirmiştir. Deneysel sonuçlarda önerdikleri modelin glokomun doğru tespitini önemli ölçüde artırdığını bildirmişlerdir [8]. Bir başka çalıșmada Christopher ve arkadașları glokomatöz optik nöropati (GON) tanısı için derin öğrenme algoritmalarından ResNet, VGG16 ve Inception-v3 modellerini kullanarak transfer öğrenmesinin etkisini değerlendirmişlerdir. GON hastalığını sağlıklı gözlerden ayırmada en iyi modelin 0.91 AUC ile Resnet50 modeli olduğunu bildirmişlerdir [9]. Bajwa et al. glokom tespiti için öncelikle retinal fundus görüntüsünden optik diski saptayan ve daha sonra onu sağlıklı veya glokomatöz olarak sınıflandıran iki așamalı bir çerçeve önermiștir. Önerilen modeli Glokom sınıflandırması için halka açlk bir veri seti olan ORIGA veri seti üzerinde değerlendirmişler ve 0.874 AUC değerine ulaștıklarını bildirmişlerdir [10]. Lee ve arkadaşları, glokomu saptamak için spektral alanlı optik koherens tomografisi kullanmıșlardır. Önerdikleri Neural Architecture Search (NASNet) mimarisinin 0,990 AUC, \% 94,7 
duyarlılık ve \% 100 özgüllük ile glokomu teșhis edebildiğini bildirdiler [11].

Literatürde yapılan ikinci çalıșma türü derin öğrenme modellerini bölütlere ayırmak için kullanmaktadır. Bisneto ve arkadaşları glokomun otomatik tespiti için bölütleme temelli çekişmeli üretici ağlar kullanmıştır. Önerilen yöntem RIM-ONE ve Drishti-GS gibi halka açı veri setleri üzerinde değerlendirilmiș ve $100 \%$ doğruluk elde etmiștir [12]. Bir bașka çalıșmada Shankaranarayana ve arkadaşları optik disk bölütleme için bir derin öğrenme modeli önermiștir. RIM-ONE veri seti üzerinde yapmıș oldukları testler neticesinde önerilen yöntemin en gelişmiş yöntemlerden daha iyi sonuçlar elde etiğini bildirmişlerdir [13]. Zilly ve arkadaşları optik disk bölütlemesi için topluluk öğrenme tabanlı evrişimli sinir ağı mimarilerini kullanan yeni bir model geliștirmiștir. Önerilen modeli DRISHTI-GS veri seti üzerinde test etmişler ve mevcut yöntemlerden daha iyi bir performans gösterdiğini bildirmişlerdir [14].

\section{Materyal ve Metot}

$\mathrm{Bu}$ bölümde çalışmada kullanılan veri seti ve yöntemler hakkında detaylı bilgi verilmiștir.

\subsection{Veri seti}

$\mathrm{Bu}$ çalışmada $\mathrm{Li}$ ve arkadaşları tarafından olușturulan büyük ölçekli bir veri seti kullanılmıştır [8].
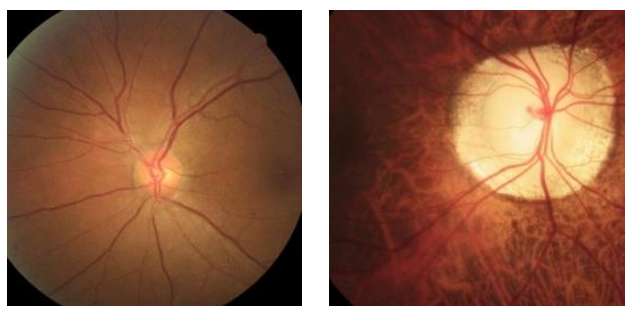

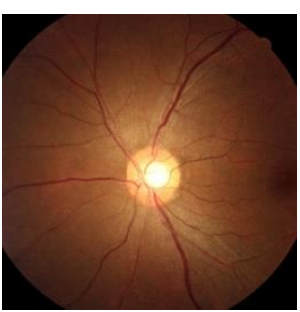

a)

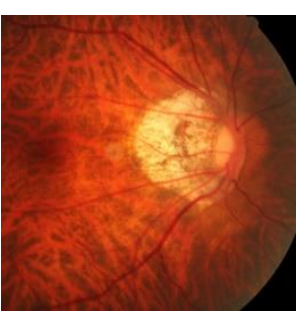

b)
Şekil 1. Örnek fundus görüntüleri a) Normal b) Glokom
Veri seti Beijing Tongren Hastanesinden elde edilen 2392 glokom ve 3432 normal olmak üzere 5824 fundus görüntüsü içermektedir. Ancak bu çalıșmada 4854 fundus görüntüsü içeren ve yalnızca araştırmacılar ile paylaşılan birinci bölümü kullanılmıștır. Bu bölümde ise 1711 glokom ve 3143 normal görüntü bulunmaktadır. Veri setindeki her bir fundus görüntüsünün pozitif veya negatif olarak etiketlenmesi alanında uzman hekimler tarafından yapılmıștır. Veri setine ait örnek fundus görüntüleri Şekil 1 'de gösterilmektedir.

\subsection{Yöntem}

Bu çalıșmada VGG16, Inception-V3, EfficientNet, DenseNet, ResNet50 ve MobileNet gibi çok gelișmiș evrișimli sinir ağl mimarileri kullanılmıştır.

VGG16 modeli, Simonyan ve Zisserman tarafından ESA modelini temel alarak geliştirilen bir mimaridir [15]. 2014 yılında yapılan ImageNet Large Scale Visual Recognition Challenge (ILSVRC- 2014) yarıșmasını \% 92,7 doğruluk puanı ile kazanmıștır. VGG16 modeli $224 \times 224$ RGB giriș katmanına sahip, 13 konvolüsyon, 3 tam bağlı katman olmak üzere toplamda 16 katmandan oluşmaktadır. VGG16, giriş görüntülerini maksimum havuzlama katmanları boyunca küçültür. Ayrıca, model 138 milyon parametreden oluşmaktadır. Modelin derinliğinin önceki diğer ESA modelleriyle karşılaştırıldığında daha derin olduğu düşünülürse, bu kadar büyük bir modelin eğitilmesi uzun bir süre almaktadır.

Google tarafından geliştirilen Inception-V3 mimarisi Derin Öğrenme Evrișimli Mimariler serisinin üçüncü sürümüdür [16]. Inception-V3, görüntü sınıflandırma alanında kullanılan en gelișmiș mimarilerden biridir. Bu mimari, birden fazla farklı boyuttaki evrişimli filtreyi yeni bir filtrede birleștiren bir bașlangıç modeli önermektedir. Bu tür bir tasarım eğitilecek parametre sayısını azaltır ve böylece hesaplama karmaşıklığını da azaltır. Model, evrișim, ortalama havuzlama, maksimum havuzlama ve tam bağlantılı katmanlar içeren simetrik ve asimetrik yapı taşlarından oluşur. Son katmanda Softmax fonksiyonu bulunan Inception-V3 mimarisi toplamda 42 katmandan oluşur ve giriște 299x299 piksel boyutlarında görüntü alır.

ImageNet sinıflandirma probleminde $66 \mathrm{M}$ parametre hesaplama yükü ile \%84.4'lük doğruluğa ulaşan EfficientNet modeli, bir grup 
evrișimli sinir ağı modeli olarak düșünülebilir. EfficientNet grubu B0-B7 arasında 8 tane modelden oluşur ve model numarası büyüdükçe hesaplanan parametre sayısı çok fazla artmaz iken ve doğruluk dikkat çekici şekilde artar [17]. Derin öğrenme mimarilerinde amaç daha küçük modeller ile daha verimli yaklașımlar ortaya koymaktır. EfficientNet modeli, diğer gelişmiş modellerden farklı olarak, modeli küçültmeye çalışırken derinlik, genişlik ve çözünürlük açısından ölçekleme yaparak daha verimli sonuçlar üretir. Bileşik ölçekleme yöntemindeki ilk adım, sabit bir kaynak kısıtlaması altında temel ağın farklı ölçeklendirme boyutları arasındaki ilişkiyi bulmak için bir ızgara(grid) arama algoritması kullanmaktadır. Bu sayede derinlik, genișlik ve çözünürlük boyutları için uygun bir ölçekleme katsayısı tespit edilir. Daha sonra bu katsayılar temel ağı istenen hedef ağa ölçeklemek için uygulanır.

Sinir ağları eğitilirken konvolüsyon ve altörnekleme işlemleri nedeniyle özellik haritalarında azalma meydana gelmektedir. Aynı zamanda katmanlar arası geçişlerde görüntü özelliğinde kayıplar olmaktadır. Görüntü özellik bilgilerinin daha etkili kullanılması için Huang tarafından DenseNet sistemi geliştirilmiştir [18]. Yapılan sistemde her bir katman diğer katmanlara ileri beslemeli bir sekilde bağlanmıştır. Bu sayede herhangi bir l katmanı kendinden önceki bütün katmanlara ait özellik bilgisine erişebilmektedir.

2015 yılında yapılan ILSVRC-2015 yarıșmasını kazanan ResNet mimarisi, kimlik haritalarını ve doğrusal olmayan çoklu katman problemini çözmek için önerilen bir mimaridir [19]. Resnet mimarisi birkaç kalıntı bloklarından oluşur. $\mathrm{Bu}$ mimari, VGG16 benzeri 3x3 filtreler kullanır ve girişte 224x224 piksellik görüntü alır.

MobileNet mimarisi 2017 yılında önerilmiștir [20]. MobileNet, esas olarak Google tarafindan mobil yerleşik terminallerin uygulanamayacağı sorununu çözmek için önerilen hafif bir derin sinir ağıdır. MobileNetV1 Ağ tasarımı, hafif bir derin sinir ağl olușturmak için derinden ayrılabilir bir evrişim kullanan modern bir mimariye dayanmaktadır. Araștırma yönü model sıkıștırması yönündedir ve ana fikri, evrişim çekirdeğinin ustaca ayrışmasıdır. Optimizasyon gecikmesini dikkate alarak ağ parametrelerini etkili bir şekilde azaltabilir.

\subsection{Değerlendirme Kriterleri}

$\mathrm{Bu}$ çalıșmada ikili sınıflandırma yapılmıștır ve kullanılan modellerin performansları Doğruluk, Duyarlılık, Özgüllük ve Kesinlik gibi farklı metrikler kullanılarak değerlendirilmiştir. Eşitlik 1-4'te verilen bu metrikler karşıtlık matrisinde elde edilen Doğru Pozitif (DP), Doğru Negatif (DN), Yanlış Pozitif (YP) ve Yanlış Negatif (YN) gibi değerler kullanılarak hesaplanır. Burada DP, doğru olarak tahmin edilen ve gerçekte de doğru olan değerleri; DN ise doğru tahmin edilen ancak gerçekte yanlış olan değerleri, YP, yanlış olarak tahmin edilen ancak gerçekte doğru olan değerleri; YN ise yanlış olarak tahmin edilen ve gerçekte de yanlış olan değerleri ifade eder.

$$
\begin{aligned}
& D o \text { ğruluk }=\frac{(D P+D N)}{(D P+Y P+D N+Y N)} \\
& \text { Duyarlılık }=\frac{D P}{D P+Y N} \\
& \text { Özgüllük }=\frac{D N}{D N+Y P} \\
& \text { Kesinlik }=\frac{D P}{D P+Y P}
\end{aligned}
$$

$\mathrm{Bu}$ çalışmada ayrıca sınıflandırma başarısını değerlendirmek için popüler metriklerden bir başkası (AUC-ROC) eğrisi de kullanılmıştır. İşlem Karakteristik (Receiver Operating Characteristic) Eğrisi, farklı eşik değerleri için hesaplanan, dikey eksen üzerinde doğru pozitiflik (duyarlılık) ve yatay eksen üzerinde yanlış pozitiflik (1- özgüllük) oranlarının yer aldığı bir grafiktir. ROC eğrisinin altında kalan alan Area Under Curve (AUC) olarak ifade edilir. AUC ne kadar büyük ise, hastalığın tahmin edilmesinde kullanılan modelin, o kadar iyi bir model olduğunu gösterir.

\section{Bulgular}

$\mathrm{Bu}$ çalışmada Li ve arkadaşları tarafından olușturulan normal sınıfa ait 3143 ve glokom sınıfına ait 1711 resim kullanılmıştır. Deneysel çalışmalar NVIDIA T80 GPU grafik kartı, Intel (R) Xeon (R) $2.00 \mathrm{GHz} \mathrm{CPU}$ ve $12 \mathrm{~GB}$ bellek ile donatılmış Google Cloud ortamında gerçekleștirilmiştir. Modellere ait tüm kodlar, 
DEÜ FMD 23(68), 521-529, 2021

Tensorflow yapısını kullanan Python dilinde yazılmış Keras Kütüphanesi ile geliştirilmiştir. https://github.com/mrtucar/glokomtespiti adresinden kodlara erişilebilir.

Çalışmada kullanılan veri seti önce \%80 eğitim ve $\% 20$ test olarak ayrılmıștır. Daha sonra eğitim veri setinin \%10'u doğrulama için kullanılmıştır. Eğitim ve doğrulama verileri sadece modelin eğitimi ve uyumu için kullanılırken test seti, modelin daha önce görmediği görüntüler üzerindeki tahmin performansını değerlendirmek için kullanılmıștır. Bu oranlara göre her bir veri kümesinde kullanılan görüntü sayısı Tablo 1'de sunulmuştur.

Tablo 1. Görüntülerin eğitim, doğrulama ve test kümelerine ayrılmış hali.

\begin{tabular}{llll}
\hline Eğitim & Doğrulama & Test & Toplam \\
\hline 3494 & 389 & 971 & 4854 \\
\hline
\end{tabular}

Bu çalıșmada kullanılan veri setinde $500 \times 500$ olan görüntüler her bir model için yeniden boyutlandırılmış ve standardize edilmiştir. Tüm modellerin eğitimi transfer öğrenimi ile gerçekleștirilmiş ve optimize edici olarak Adam, loss fonksiyonu olarak çapraz entropi kullanılmıștır. Her bir model için eğitim 50 adımda gerçekleștirilmiștir. Eğitim sürecinde her adım sonrasında doğrulama verileri ile modelin bașarısı hesaplanmıș ve aşırı öğrenmeyi engellemek için en düșük doğrulama hata oranına sahip model ağırlığı saklanarak test için kullanılmıştır. Deneysel çalıșmalarda kullanılan modellere ait ana parametreler Tablo 2'deki gibidir.

Tablo 2. Modellere ait ana parametreler.

\begin{tabular}{llcr}
\hline Model Adı & $\begin{array}{l}\text { Giriş } \\
\text { boyutu }\end{array}$ & $\begin{array}{l}\text { Mini } \\
\text { Topluluk } \\
\text { Değeri }\end{array}$ & $\begin{array}{l}\text { Öğrenme } \\
\text { Oranı }\end{array}$ \\
\hline VGG16 & $224 \times 224 \times 3$ & 64 & 0.00005 \\
InceptionV3 & $299 \times 299 \times 3$ & 32 & 0.001 \\
EfficientNet & $224 \times 224 \times 3$ & 32 & 0.00005 \\
DenseNet & $224 \times 224 \times 3$ & 16 & 0.00005 \\
ResNet50 & $224 \times 224 \times 3$ & 32 & 0.001 \\
MobileNet & $224 \times 224 \times 3$ & 64 & 0.00005 \\
\hline
\end{tabular}

Tüm modellerin test veri setinde elde ettiği doğruluk, duyarlılık, özgüllük ve kesinlik değerleri ile toplam eğitim süreleri Tablo 3' te verilmiştir. Tablo 3'te görüldüğü üzere tüm modeller birbirine oldukça yakın doğruluk değerleri elde etmiștir. En yüksek doğruluk değerini \%96.19 ile DenseNet modeli; en düşük doğruluk değerini ise \%92.79 ile MobileNet modeli sağlamıștır. Eğitim süresine bakıldığında MobileNet modeli en düşük eğitim süresine sahip model olurken VGG16 modelinin eğitimi en uzun sürede tamamlanmıştır. En başarılı sonucu veren DenseNET modelinin ise eğitim süresinin 4293 saniye olduğu görülmektedir.

Tablo 3. Modellere ait sonuçlar.

\begin{tabular}{lrrrrc}
\hline & Doğruluk & Duyarlılık & Özgüllük & Kesinlik & $\begin{array}{c}\text { Toplam eğitim } \\
\text { süresi (saniye) }\end{array}$ \\
\hline VGG16 & 95.98 & 95.97 & 95.97 & 95.33 & 7067 \\
InceptionV3 & 95.06 & 94.98 & 94.98 & 94.30 & 3961 \\
EfficientNet & 95.37 & 94.76 & 94.76 & 95.06 & 2995 \\
DenseNet & $\mathbf{9 6 . 1 9}$ & $\mathbf{9 6 . 0 6}$ & $\mathbf{9 6 . 0 6}$ & $\mathbf{9 5 . 6 4}$ & 4293 \\
ResNet50 & 94.44 & 93.91 & 93.91 & 93.91 & 3492 \\
MobileNet & 92.79 & 92.90 & 92.90 & 91.68 & $\mathbf{1 6 9 2}$ \\
\hline
\end{tabular}

Modellerin performanslarını değerlendirmek için karşıtlık matrisleri (confusion matrix) elde edilmiştir. Her bir model için elde edilen karşıtlık matrisleri Şekil 2'de verilmiştir. 
DEÜ FMD 23(68), 521-529, 2021
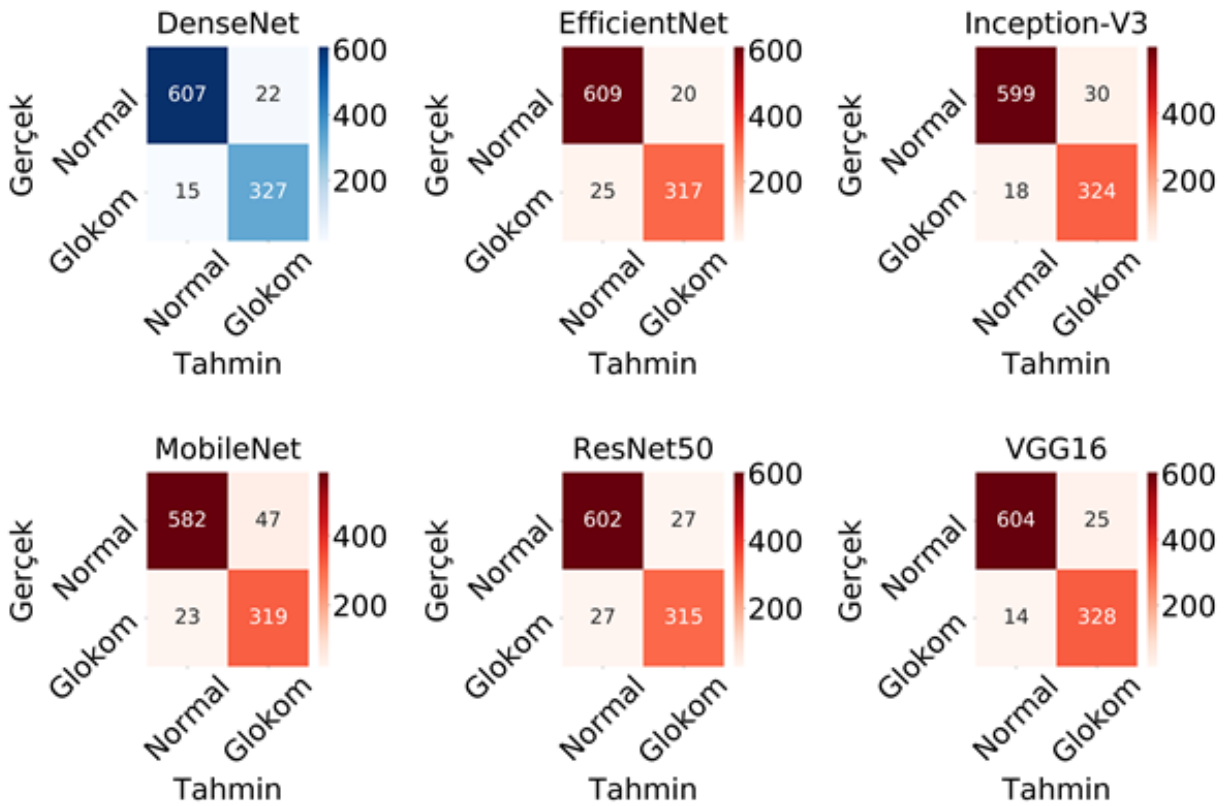

Şekil 2. Modellere ait karşıtlık matrisler

Deneysel çalıșmalar ile elde edilen sonuçlar DenseNet mimarisinin tüm performans metriklerinde en yüksek değerleri ürettiğini göstermiştir. Şekil 3 tüm modeller için test veri setinde elde edilen doğrulukları göstermektedir.
Tüm modellerin eğitimi sırasında, eğitim ve doğrulama kümelerinde elde edilen doğruluk ve hata eğrileri Şekil 4 'te verilmiştir.

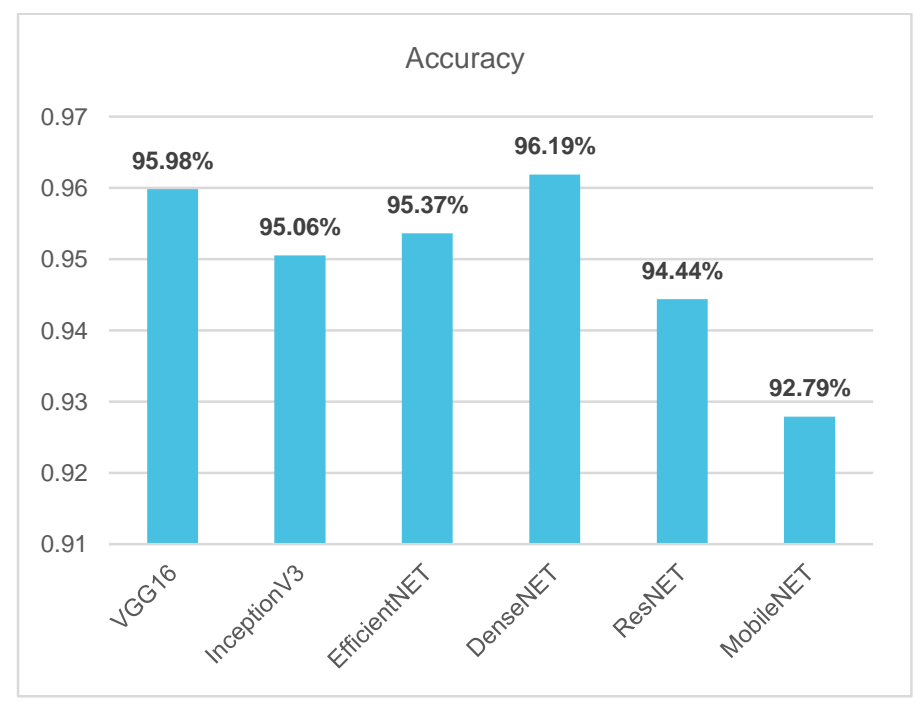

Şekil 3. Modellere ait doğruluk değerleri 

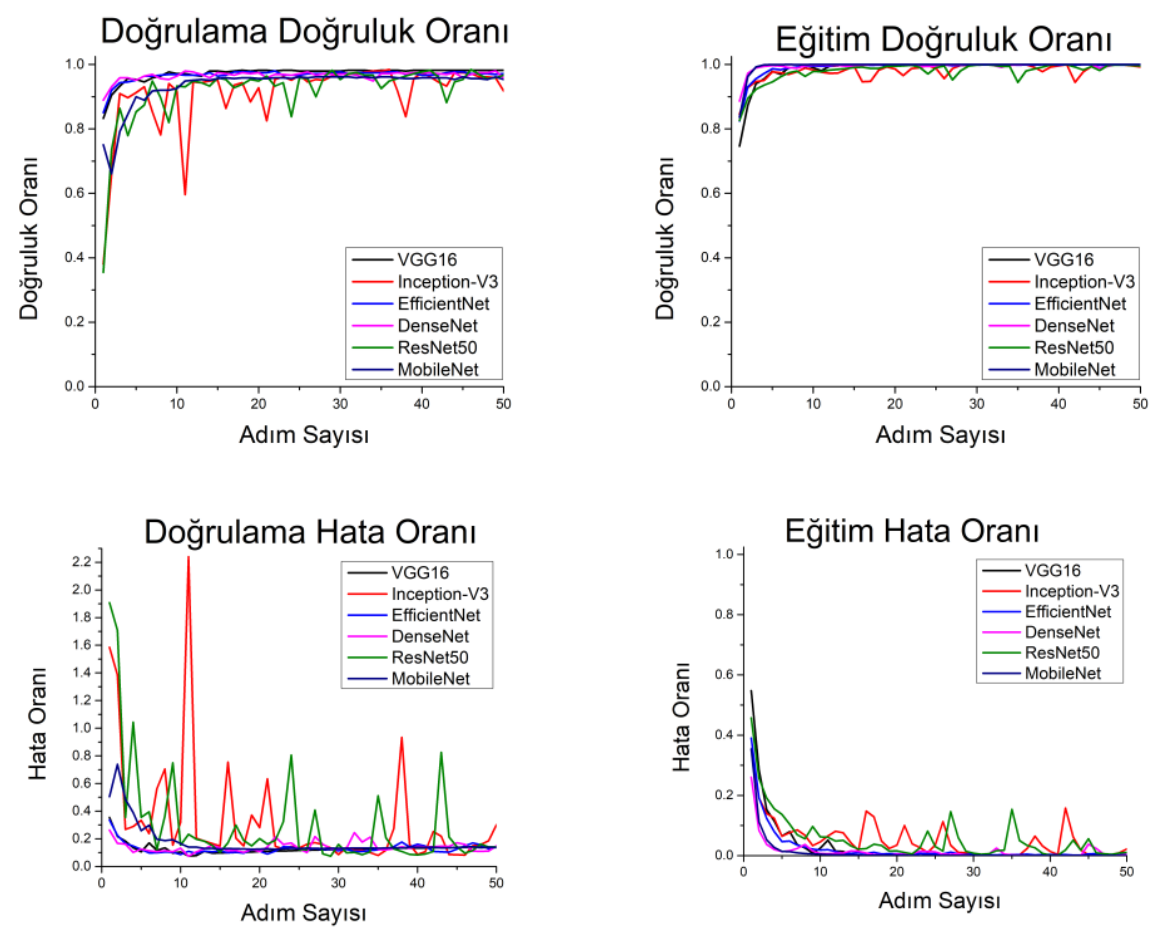

Şekil 4. Eğitim ve doğrulama kümelerine ait doğruluk ve hata değerleri

Çalışmada kullanılan tüm modellerin bașarısı ayrıca (AUC-ROC) eğrileri ile de değerlendirilmiştir. ROC eğrisi ve AUC değerleri Şekil 5'te verilmiştir.

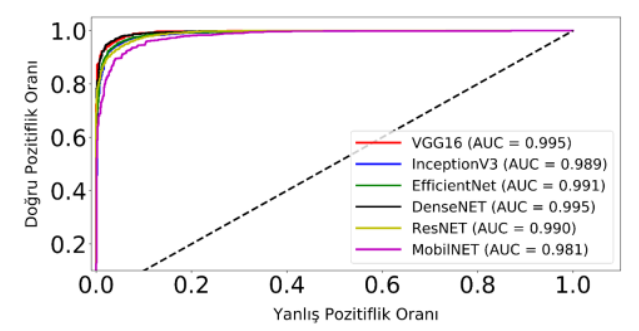

Şekil 5. Modellere ait ROC eğrisi ve AUC değeri

\section{Tartışma ve Sonuç}

$\mathrm{Bu}$ çalışmada fundus görüntülerinden glokom vakalarının otomatik tespiti ve sinıflandırılması için çeşitli ESA mimarileri kullanılmıştır. Yöntemin başarısını karşılaştırmak için, glokom tanısında derin öğrenme yöntemleri kullanan önceki çalışmalara ait yöntem, veri sayısı ve başarı oranı Tablo 4'te verilmiştir.

Tablo 4'ten görüleceği üzere glokom ve normal görüntülerin ikili sınıflandırılmasında halka açık bazı veri setleri kullanılarak çalışmalar yapıldı ancak bu veri setlerinde glokom hastalarına ait görüntülerin sınırlı olduğu tespit edilmiștir. Yapılan bazı çalışmalarda çeşitli veri setleri birleştirilerek sınıflandırma yapıldığı görülmüştür. ESA modellerinin doğru sinıflandırma yapabilmesinde veri seti büyüklüğü önemli bir parametredir. $\mathrm{Bu}$ çalışmada oldukça büyük bir veri setine ait görüntülerin kullanılmasının çalışmanın başarısını artırdığı görülmüștür. Çalıșma sonucunda DenseNet mimarisi ile elde edilen \%96.19'luk doğruluk oranı oldukça yüksek bir değere sahiptir. Bunun yanı sıra çalışmada önerilen çözüm yaklaşımı literatürde aynı veri setini kullanan $\mathrm{Li}$ ve diğ.[8] tarafından geliştirilen model ile karşılaştırıldığında, birbirine çok yakın sonuçlar elde edildiği görülmektedir. Genel olarak modelin, göz doktorlarının klinik tanılarını kontrol etmelerine yardımcı olabileceği düşünülmektedir.

Gelecek çalışmalarda, yeni bir derin öğrenme modeli geliştirilerek glokom hastalı̆̆ının tespitinde daha başarılı sonuçlar elde edilmesi amaçlanmaktadır. 
DEÜ FMD 23(68), 521-529, 2021

Tablo 4. Önceki çalışmalara ait sonuçlar.

\begin{tabular}{|c|c|c|c|c|}
\hline Yazar & Yöntem & Veri Seti & $\begin{array}{r}\text { Veri } \\
\text { sayısı }\end{array}$ & $\begin{array}{c}\text { Başarı } \\
\text { Oranı (\%) }\end{array}$ \\
\hline Chen ve diğ. [4] & ESA & ORIGA ve SCES veri setleri & 1676 & 88,70 \\
\hline Raghavendra ve diğ. [5] & 18 katmanlı ESA & $\begin{array}{l}\text { Kasturba Medikal Kolejinden } \\
\text { elde edilen özel veri seti }\end{array}$ & 1426 & 98.13 \\
\hline Chai ve diğ. [6] & Çok branşlı sinir ağı & Özel veri seti & 2554 & 91.51 \\
\hline Fu ve diğ. [7] & $\begin{array}{l}\text { Topluluk } \\
\text { öğrenmesi }\end{array}$ & $\begin{array}{l}\text { ORIGA(Eğitim veri seti) SCES ve } \\
\text { SINDI (Test Veri Seti) }\end{array}$ & 650 & 84.29 \\
\hline Li ve diğ. [8] & Dikkat temelli ESA & $\begin{array}{l}\text { Beijing Tangren Hastanesinden } \\
\text { elde edilen özel veri seti }\end{array}$ & 5824 & 95.30 \\
\hline $\mathrm{Bu}$ çalışma & ESA (DenseNet) & $\begin{array}{l}\text { Li ve diğ. [8] tarafindan } \\
\text { olușturulan veri seti }\end{array}$ & 4854 & 96.19 \\
\hline
\end{tabular}

\section{Teşekkür}

Yazar, glokom ve normal fundus görüntülerini içeren büyük ölçekli veri setine erişim izni için $\mathrm{Li}$ ve arkadașlarına teșekkür eder.

\section{Kaynakça}

[1] Y.-C. Tham, X. Li, T. Y. Wong, H. A. Quigley, T. Aung, and C.-Y. Cheng, "Global prevalence of glaucoma and projections of glaucoma burden through 2040: a systematic review and meta-analysis," Ophthalmology, vol. 121, no. 11, pp. 2081-2090, 2014.

[2] V. Gulshan et al., "Development and validation of a deep learning algorithm for detection of diabetic retinopathy in retinal fundus photographs," Jama, vol. 316, no. 22 , pp. 2402-2410, 2016.

[3] C. S. Lee, D. M. Baughman, and A. Y. Lee, “Deep learning is effective for classifying normal versus age-related macular degeneration OCT images," Ophthalmol. Retin., vol. 1, no. 4, pp. 322-327, 2017.

[4] X. Chen, Y. Xu, D. W. K. Wong, T. Y. Wong, and J. Liu, "Glaucoma detection based on deep convolutional neural network," in 2015 37th annual international conference of the IEEE engineering in medicine and biology society (EMBC), 2015, pp. 715-718.

[5] U. Raghavendra, H. Fujita, S. V Bhandary, A. Gudigar, J. H. Tan, and U. R. Acharya, “Deep convolution neural network for accurate diagnosis of glaucoma using digital fundus images," Inf. Sci. (Ny)., vol. 441, pp. 41-49, 2018.
[6] Y. Chai, H. Liu, and J. Xu, "Glaucoma diagnosis based on both hidden features and domain knowledge through deep learning models," Knowledge-Based Syst., vol. 161, pp. 147-156, 2018.

[7] H. Fu et al., "Disc-aware ensemble network for glaucoma screening from fundus image," IEEE Trans. Med. Imaging, vol. 37, no. 11, pp. 2493-2501, 2018.

[8] L. Li, M. Xu, X. Wang, L. Jiang, and H. Liu, "Attention based glaucoma detection: A large-scale database and CNN Model," in Proceedings of the IEEE Conference on Computer Vision and Pattern Recognition, 2019, pp. 10571-10580.

[9] M. Christopher et al., "Performance of deep learning architectures and transfer learning for detecting glaucomatous optic neuropathy in fundus photographs," Sci. Rep., vol. 8, no. 1, pp. 1-13, 2018.

[10] M. N. Bajwa et al., "Two-stage framework for optic disc localization and glaucoma classification in retinal fundus images using deep learning," BMC Med. Inform. Decis. Mak., vol. 19, no. 1, p. 136, 2019.

[11] J. Lee, Y. K. Kim, K. H. Park, and J. W. Jeoung, "Diagnosing Glaucoma With Spectral-Domain Optical Coherence Tomography Using Deep Learning Classifier," J. Glaucoma, vol. 29, no. 4, pp. 287-294, 2020.

[12] T. R. V. Bisneto, A. O. de Carvalho Filho, and D. M. V. Magalhães, "Generative adversarial network and texture features applied to automatic glaucoma detection," Appl. Soft 


\section{DEÜ FMD 23(68), 521-529, 2021}

Comput., vol. 90, p. 106165, 2020.

[13] S. M. Shankaranarayana, K. Ram, K. Mitra, and M. Sivaprakasam, "Joint optic disc and cup segmentation using fully convolutional and adversarial networks," in Fetal, Infant and Ophthalmic Medical Image Analysis, Springer, 2017, pp. 168-176.

[14] J. Zilly, J. M. Buhmann, and D. Mahapatra, "Glaucoma detection using entropy sampling and ensemble learning for automatic optic cup and disc segmentation," Comput. Med. Imaging Graph., vol. 55, pp. 28-41, 2017.

[15] K. Simonyan and A. Zisserman, "Very deep convolutional networks for large-scale image recognition," arXiv Prepr. arXiv1409.1556, 2014.

[16] C. Szegedy, V. Vanhoucke, S. Ioffe, J. Shlens, and Z. Wojna, "Rethinking the inception architecture for computer vision," in Proceedings of the IEEE conference on computer vision and pattern recognition, 2016, pp. 2818-2826.
[17] M. Tan and Q. V. Le, "EfficientNet: Rethinking model scaling for convolutional neural networks," 36th Int. Conf. Mach. Learn. ICML 2019, vol. 2019-June, pp. 10691-10700, 2019.

[18] G. Huang, Z. Liu, L. Van Der Maaten, and K. Q. Weinberger, "Densely connected convolutional networks," in Proceedings of the IEEE conference on computer vision and pattern recognition, 2017, pp. 4700-4708.

[19] K. He, X. Zhang, S. Ren, and J. Sun, "Deep residual learning for image recognition," Proc. IEEE Comput. Soc. Conf. Comput. Vis. Pattern Recognit., vol. 2016-Decem, pp. 770778, 2016, doi: 10.1109/CVPR.2016.90.

[20] A. G. Howard et al., "Mobilenets: Efficient convolutional neural networks for mobile vision applications," arXiv Prepr. arXiv1704.04861, 2017. 